\title{
Noncontrast Ct Findings for Spontaneous Passage of Ureteral Stones
}

\author{
Eyup Burak Sancak ${ }^{1}$, Omer Levent Tuncay ${ }^{2}$, Zafer Sınık², Tahir Turan ${ }^{2}$ \\ Department of Urology, Canakkale Onsekiz Mart University, Faculty of Medicine, Canakkale, \\ Turkey $^{1}$ \\ Department of Urology, Pamukkale University, Faculty of Medicine, Denizli, Turkey ${ }^{2}$
}

\begin{abstract}
:
Objective: The majority of ureteral stones with diameter smaller than $4 \mathrm{~mm}$ pass, while the majority of stones larger than $10 \mathrm{~mm}$ require intervention. The aim of this study is to evaluate patients with stones identified as 4$10 \mathrm{~mm}$ in size and determine the similarities and differences between patients who passed stones spontaneously (PPSS) and patients who required intervention (PRI).

Methods: The study included 34 patients with complaint of acute flank pain and ureteral stones identified as 4$10 \mathrm{~mm}$ in size. The clinical data and non-contrast computed tomography (NCCT) images of patients were evaluated.

Results: The mean age of patients was $42.5 \pm 14.5$ (20-62) years. While 13 patients spontaneously passed stones, 21 patients required intervention. The mean length of stones in the PPSS group was $5.86 \pm 1.46 \mathrm{~mm}$, while this was $7.38 \pm 1.76 \mathrm{~mm}$ in the PRI group $(p=0.025)$. The mean volume of PPSS stones was calculated as $181.67 \pm 148.41 \mathrm{~mm}^{3}$, while the mean volume of PRI stones was $424.22 \pm 273.22 \mathrm{~mm}^{3}(p=0.004)$. Findings identified to be in favor of spontaneous passage included small volume of ureteral stones and distal location, presence of perinephric fat stranding (PFS), hydronephrosis and lack of tissue-rim sign (TRS). The presence of PFS and absence of TRS had specificity of $100 \%$ and positive predictive value of $100 \%$ to determine spontaneous passage.
\end{abstract}

Conclusions: In patients applying with renal colic linked to ureteral stones, evaluating ureteral stones and secondary signs with NCCT may determine which patients do not require intervention.

Keywords: spontaneous passage, ureteral stone, non-contrast spiral tomography, tissue rim sign, perinephric fat stranding

\section{INTRODUCTION}

The incidence and prevalence of urinary system stone disease is increasing globally. ${ }^{1}$ Urolithiasis accounts for $16 \%$ of urologic applications and $1-2 \%$ of all hospital applications. As it generally affects people in the most active stage of life, it causes a serious rate of morbidity and productivity loss. ${ }^{2}$ While $60 \%$ of ureteral stones spontaneously pass, $40 \%$ require intervention. ${ }^{3}$ The decision for treatment is affected by many factors such as size of the ureteral stone, localization and patient choice. Ureteral stones larger than $1 \mathrm{~cm}$ generally have intervention planned with minimally invasive or invasive methods. However, majority of of ureteral stones smaller than $4 \mathrm{~mm}$ are reported to pass spontaneously. ${ }^{4,5}$ The main difficulty for urologists deciding on treatment is ureteral stones with sizes from $4-10 \mathrm{~mm}$.

Current European Association of Urology guideline for the evaluation of patients applying with acute flank pain recommend non-contrast computed tomography (NCCT), with high sensitivity and specificity and ability to distinguish non-stone pathologies, as the standard imaging method. ${ }^{4}$ NCCT may be used to determine secondary signs developing linked to stones such as tissue-rim sign (TRS), perinephric fat stranding (PFS), hydroureteronephrosis and difference of renal parenchymal attenuation (DRPA), as well as stone size, localization and density. It is reported that these secondary signs may provide clues related to the spontaneous passage of stones. ${ }^{3,6}$ However, there is no study evaluating NCCT only for ureteral stones from $4-10 \mathrm{~mm}$. In our study we planned to evaluate NCCT images of patients with 4-10 mm ureteral stones to determine the similarities and differences between patients who passed stones spontaneously (PPSS) and patients who required intervention (PRI). 


\section{Patients AND Methods}

After receiving permission from the institutional ethics committee, patients applying to Pamukkale University, Faculty of Medicine, Urology Department with acute flank pain and found to have 4-10 $\mathrm{mm}$ diameter ureteral stones were included in the study. These patients abided by the condition of only having a single ureteral stone with size from 4-10 mm. Patients with solitary kidney, pregnancy or suspected pregnancy, abnormal ureteral anatomy, severe symptoms resistant to conservative medical treatment, high creatinine, infection accompanying ureteral stone or obstructive pyelonephritis were excluded from the study. Additionally patients with urologic or non-urologic malignancy were not included in the study. The clinical data and NCCT (Philips Mx8000) images of 34 patients abiding by the criteria were evaluated. The patients were called for check-up 2 weeks later. Patients with no movement of ureteral stones and symptomatic patients had intervention planned. The definite diagnosis of stone was confirmed by showing spontaneously passed stones or seeing the stone during Ureterorenoscopy (URS).

Spiral tomography screening was completed at $120 \mathrm{kV}, 17.5 \mathrm{~mm} / 1 \mathrm{~s}$ table velocity, pitch $1.75 / 1,2 \mathrm{x}$ $6.5 \mathrm{~mm}$ collimation and $3.2 \mathrm{~mm}$ reconstruction thickness. NCCT images were examined by 2 experienced radiologists. The longest diameter of the stone, localization (proximal, middle, distal ureter), density [in Hounsfield units (HU)], degree of hydronephrosis (mild, moderate, severe), thickening of renal fascia, DRPA, PFS (Figure 1), ratio of ureteral diameter/opposite ureteral diameter (UD/OUD), TRS (rings of soft tissue density around the ureteral stone) (Figure 2) and widest ureteral diameter were noted. The stone volume observed on 3 dimensional reconstruction using the device's software was calculated using the tissue volume choice (Figure 3). DRPA was accepted as kidney density of the asymptomatic side being 5 or more HU higher than symptomatic kidney density (Figure 4). The widest diameter of the ureter was measured on the axial plane proximal to the ureteral stone. Care was taken not to mistakenly measure the pelvis in patients with extrarenal pelvis. PPSS and PRI were compared in terms of results obtained from clinical data and NCCT images.

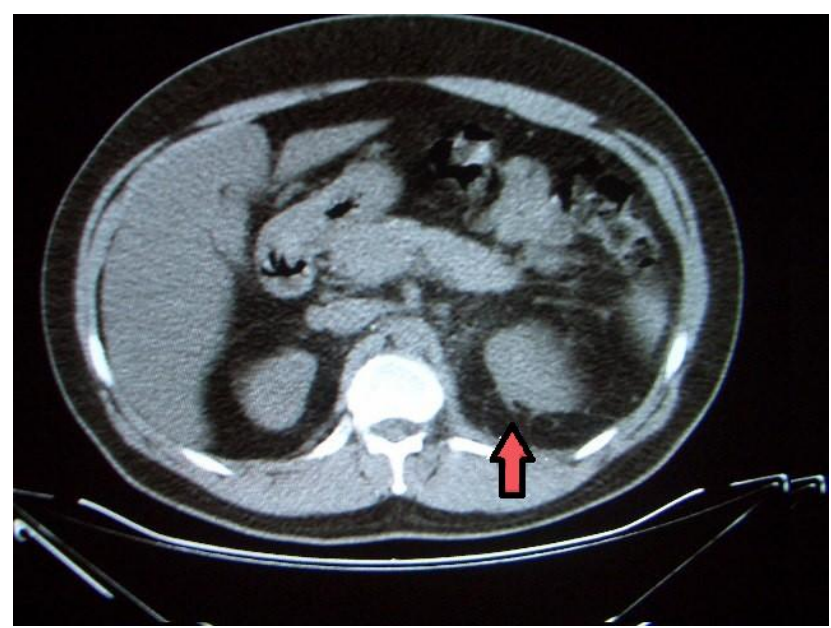

Figure1. PFS Around the Lower Pole of the Left Kidney, More Clearly Seen Compared to the Contralateral Kidney

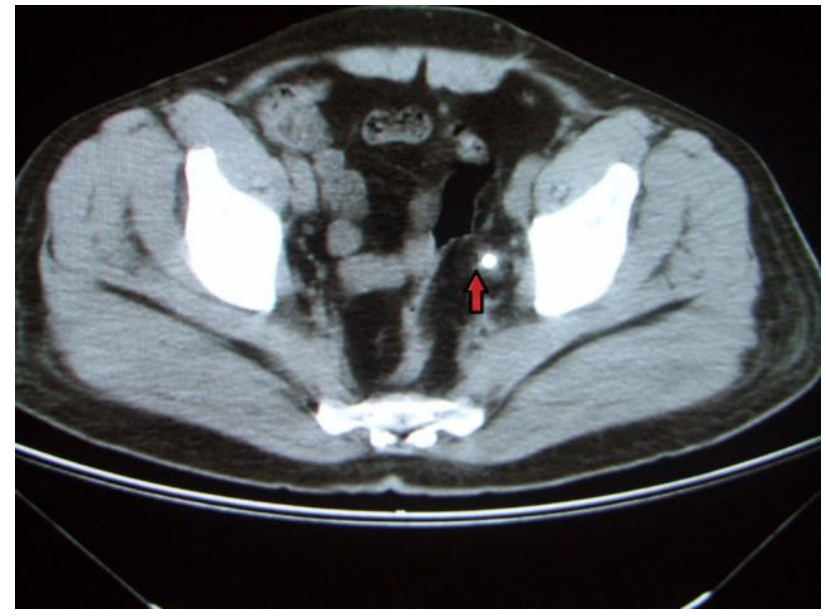

Figure2. TRS, Shown with White arrow, Forming Due to Edema of Ureteral Tissue around Left Ureteral Distal Stone 


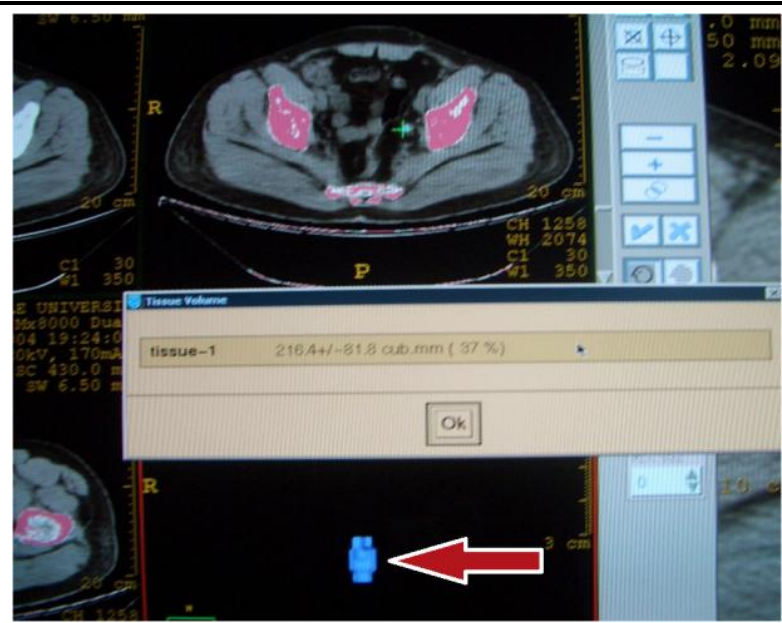

Figure3. Volume of Ureteral Stones Calculated with Tissue Volume Choice After 3-Dimensional Reconstruction With Computed Tomography Device Software. The 3-Dimensional Reconstruction of the Stone Is Shown With the Arrow

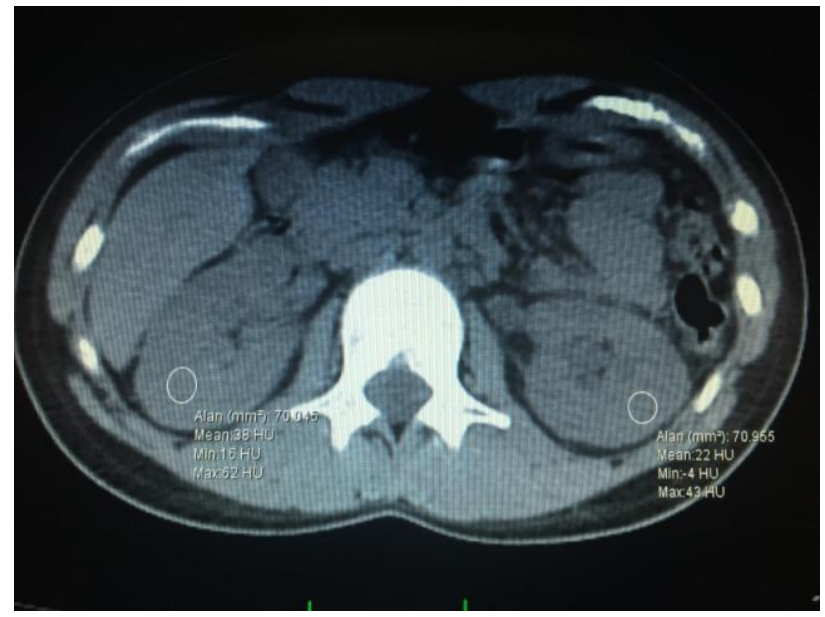

Figure4. Measurement of Differences in Renal Parenchymal Attenuation Between Both Kidneys

\section{Statistical Analysis}

The patients with spontaneous passage were statistically compared with patients requiring intervention. Sex, stone laterality, perinephric fluid collection, thickening of renal fascia, unilateral renal growth and TRS were analyzed with Fisher's Exact Chi-Square test. PFS, DRPA and irregular stone boundaries were analyzed with Yate's chi-square test, while stone localization and hydronephrosis were analyzed with the chi-square test. The Mann-Whitney $U$ test was used to evaluate patient age, stone size, volume, density and UD/OUD. Additionally the correlation between longest diameter and volume of ureteral stones was assessed with the Pearson correlation test.

\section{Results}

Of patients in the study, 24 were male and 10 were female. The mean age of patients was $42.5 \pm 14.5$ (20-62) years. At two week check-up, 10 of the 34 patients had passed the stone while 3 passed the stone before the next check-up (within the next two weeks) (PPSS group). The 21 patients who did not pass the stone had intervention with ESWL or URS (PRI group).

The mean length of stones with spontaneous passage was $5.86 \pm 1.46 \mathrm{~mm}$, while this was $7.38 \pm 1.76$ $\mathrm{mm}$ in the group requiring intervention $(\mathrm{p}=0.025)$. The mean volume of PPSS stones was calculated as $181.67 \pm 148.41$, while the mean volume of PRI stones was $424.22 \pm 273.22 \mathrm{~mm}^{3}(\mathrm{p}=0.004)$. When a limit value of $295 \mathrm{~mm}^{3}$ is taken for volume, the sensitivity was $84.6 \%$ and negative predictive value was $85.7 \%$ for spontaneous passage.

There was no association between spontaneous passage and patient age, sex, laterality of stone density, thickening of renal fascia and DRPA (Table 1). The ratio of widest ureteral diameter on the side with ureteral stone to the side without varied from 1.07 to 8.7. There was no significant difference found for spontaneous passage $(p=0.296)$. The widest ureteral diameter varied from 2.60 
$\mathrm{mm}$ to $21.00 \mathrm{~mm}$. There wasn't statistically significant difference found between widest diameter of ureter and spontaneous passage $(\mathrm{p}=0.107)$.

Small size of ureteral stone, distal localization, presence of PFS, hydronephrosis and lack of TRS were identified as findings in favor of spontaneous passage. PFS and absence of TRS had calculated sensitivity of $53.8 \%$, specificity of $100 \%$, positive predictive value of $100 \%$ and negative predictive value of $77.8 \%$ to determine spontaneous passage. The results are summarized in Table 1.

Table1. Comparison of PPSS and PRI Groups in Terms of Basic Clinical Parameters and Noncontrast Computed Tomography Images

\begin{tabular}{|c|c|c|c|c|}
\hline & $\underset{(n=34)}{\text { All patients }}$ & $\underset{(n=13)}{\text { PPSS Group* }}$ & $\underset{(\mathrm{n}=21)}{\text { PRI Group* }}$ & $p$ value $* *$ \\
\hline $\begin{array}{l}\text { Gender } \\
\text { - Man } \\
\text { - Woman } \\
\end{array}$ & $\begin{array}{l}24 \\
8 \\
\end{array}$ & $\begin{array}{l}16(67 \%) \\
4(50 \%)\end{array}$ & $\begin{array}{l}8(33 \%) \\
4(50 \%) \\
\end{array}$ & 0.451 \\
\hline $\begin{array}{l}\text { Age } \\
- \text { Mean } \\
\text { - Standard deviation } \\
\end{array}$ & $\begin{array}{l}42.50 \\
14.5 \\
\end{array}$ & $\begin{array}{l}41.50 \\
12.15 \\
\end{array}$ & $\begin{array}{l}43.25 \\
15.25 \\
\end{array}$ & 0.385 \\
\hline $\begin{array}{l}\text { Stone diameter } \\
-\quad \text { Mean } \\
\text { - Standard deviation }\end{array}$ & $\begin{array}{l}6.80 \\
1.79\end{array}$ & $\begin{array}{l}5.86 \\
1.46\end{array}$ & $\begin{array}{l}7.38 \\
1.76\end{array}$ & 0.025 \\
\hline $\begin{array}{l}\text { Stone volume } \\
-\quad \text { Mean } \\
- \text { Standard deviation } \\
\end{array}$ & $\begin{array}{l}331.48 \\
259.93 \\
\end{array}$ & $\begin{array}{l}181.67 \\
148.41 \\
\end{array}$ & $\begin{array}{l}424.22 \\
273.22 \\
\end{array}$ & 0.004 \\
\hline $\begin{array}{l}\text { Stone localization } \\
-\quad \text { Upper ureter } \\
-\quad \text { Middle ureter } \\
-\quad \text { Distal ureter } \\
\end{array}$ & $\begin{array}{l}9 \\
9 \\
16\end{array}$ & $\begin{array}{l}2(22 \%) \\
1(11 \%) \\
10(63 \%)\end{array}$ & $\begin{array}{l}7(78 \%) \\
8(89 \%) \\
6(37 \%) \\
\end{array}$ & 0.030 \\
\hline $\begin{array}{l}\text { Stone laterality } \\
- \text { - Right } \\
-\quad \text { Left } \\
\end{array}$ & $\begin{array}{l}10 \\
24 \\
\end{array}$ & $\begin{array}{l}4(40 \%) \\
9(38 \%) \\
\end{array}$ & $\begin{array}{l}6(60 \%) \\
15(62 \%) \\
\end{array}$ & 0.928 \\
\hline $\begin{array}{l}\text { Stone density (Hounsfield Unit) } \\
-\quad \text { Mean } \\
-\quad \text { Standard deviation } \\
\end{array}$ & $\begin{array}{l}554.17 \\
240.25 \\
\end{array}$ & $\begin{array}{l}488.41 \\
245.02 \\
\end{array}$ & $\begin{array}{l}660.93 \\
197.37 \\
\end{array}$ & 0.129 \\
\hline $\begin{array}{l}\text { Hydronephrosis } \\
\text { - No } \\
\text { - Minimal } \\
\text { - Moderate } \\
\text { - Severe }\end{array}$ & $\begin{array}{l}3 \\
9 \\
15 \\
7\end{array}$ & $\begin{array}{l}3(100 \%) \\
4(44 \%) \\
5(33 \%) \\
1(14 \%)\end{array}$ & $\begin{array}{l}0 \\
5(56 \%) \\
10(67 \%) \\
6(86 \%)\end{array}$ & 0.018 \\
\hline $\begin{array}{l}\text { Perinephric fat stranding } \\
- \text { Yes } \\
- \text { No }\end{array}$ & $\begin{array}{l}15 \\
19 \\
\end{array}$ & $\begin{array}{l}9(60 \%) \\
4(21 \%) \\
\end{array}$ & $\begin{array}{l}6(40 \%) \\
15(79 \%) \\
\end{array}$ & 0.049 \\
\hline $\begin{array}{l}\text { Thickening of renal fascia } \\
-\quad \text { Yes } \\
- \text { No } \\
\end{array}$ & $\begin{array}{l}12 \\
22 \\
\end{array}$ & $\begin{array}{l}6(50 \%) \\
7(32 \%) \\
\end{array}$ & $\begin{array}{l}6(50 \%) \\
15(68 \%) \\
\end{array}$ & 0.462 \\
\hline $\begin{array}{llll}\text { Difference } & \text { of } & \text { renal } & \text { parenchymal } \\
\text { attenuation } & & & \\
- \text { Yes } & & & \\
- \text { No } & & & \\
\end{array}$ & $\begin{array}{l}17 \\
17 \\
\end{array}$ & $\begin{array}{l}4(24 \%) \\
9(53 \%) \\
\end{array}$ & $\begin{array}{l}13(76 \%) \\
8(47 \%) \\
\end{array}$ & 0.131 \\
\hline $\begin{array}{l}\text { Tissue rim sign } \\
-\quad \text { Yes } \\
- \text { No } \\
\end{array}$ & $\begin{array}{l}22 \\
12 \\
\end{array}$ & $\begin{array}{l}4(18 \%) \\
9(75 \%) \\
\end{array}$ & $\begin{array}{l}18(82 \%) \\
3(25 \%) \\
\end{array}$ & 0.002 \\
\hline $\begin{array}{l}\text { Hydroureter } \\
-\quad \text { Yes } \\
\text { - No }\end{array}$ & $\begin{array}{l}5 \\
29\end{array}$ & $\begin{array}{l}4(80 \%) \\
19(66 \%)\end{array}$ & $\begin{array}{l}1(20 \%) \\
10(34 \%)\end{array}$ & 0.059 \\
\hline $\begin{array}{l}\text { Perinephric fat stranding }(+) \\
\text { Tissue rim sign }(-) \\
-\quad \text { Yes } \\
-\quad \text { No } \\
\end{array}$ & $\begin{array}{l}7 \\
27 \\
\end{array}$ & $\begin{array}{l}7(100 \%) \\
6(22 \%)\end{array}$ & $\begin{array}{l}0 \\
21(88 \%)\end{array}$ & $<0.001$ \\
\hline
\end{tabular}

* PPSS: Patients who passed stones spontaneously; PRI: patients who required intervention.

** Statistically significant at $p<0.05$. This $p$-value is compared to the PPSS and PRI groups. 


\section{DISCUSSION}

This paper evaluated the NCCT images of patients with 4-10 mm size ureteral stones and is the first study to distinguish patients requiring intervention from those who do not require intervention. For treatment of ureteral stones, there are a variety of treatment choices ranging from observation and minimally invasive treatments to open or laparoscopic stone removal. While $60 \%$ of ureteral stones spontaneously pass, $40 \%$ require intervention. ${ }^{3}$ During active surveillance patients may be exposed to unwanted complications such as renal colic attacks and pyelonephritis. In patients with active treatment of ureteral stones, there may be complications related to the intervention. The majority of ureteral stones smaller than $4 \mathrm{~mm}$ pass, while the majority of stones larger than $10 \mathrm{~mm}$ require intervention. ${ }^{4,7}$ Many urologists experience a dilemma of whether to wait for the stone to pass or to intervene, especially for 4-10 $\mathrm{mm}$ ureteral stones.

Due to its high accuracy, and the short time needed to perform it without contrast, NCCT has become the standard for diagnosing acute flank pain, and has replaced intravenous urography (IVU). In addition to stone size and localization, NCCT may determine signs related to the stone (volume, density) and secondary signs (TRS, PFS, thickening of renal fascia, hydronephrosis, etc.). ${ }^{3,6}$ The standard imaging method for diagnosis and treatment planning of ureteral stones, evaluation of NCCT findings to determine stones with spontaneous passage will be very beneficial to both patient and clinician.

Coll et al. reported that spontaneous passage of ureteral stones was affected by stone size and localization. ${ }^{7}$ While $95 \%$ of $4 \mathrm{~mm}$ and smaller stones pass spontaneously, only $25 \%$ of stones larger than $9 \mathrm{~mm}$ pass spontaneously. ${ }^{4,7}$ Erdogru et al. found the mean size of spontaneously passed stones was $4.37 \pm 1.63 \mathrm{~mm}$, with mean size of non-passing stones $7.35 \pm 1.81 \mathrm{~mm} .{ }^{6}$ In our study, in spite of only including patients with $4-10 \mathrm{~mm}$ ureteral stones, the mean longest diameter of PPSS ureteral stones was $5.86 \pm 1.46 \mathrm{~mm}$ while the mean for PRS stones was $7.38 \pm 1.76 \mathrm{~mm}(\mathrm{p}=0.025)$. Again Coll et al. researched stone localization and spontaneous passage and found that the rate of spontaneous passage was $48 \%$ of proximal ureteral stones, $60 \%$ for mid ureteral stones and $75 \%$ for distal ureteral stones. In our study, the spontaneous passage rates for proximal, middle and distal ureter were $22 \%$, $11 \%$ and $66 \%(\mathrm{p}=0.030)^{7}$

Zorba et al. in a current publication calculated each of the 3 dimensions of ureteral stones and multiplied by 0.52 to calculate stone volume. ${ }^{8}$ In the PPSS and PRI groups the stone volumes were found to be $41.2 \pm 35.5$ and $128.1 \pm 91.1 \mathrm{~mm}^{3}$, respectively ( $\mathrm{p}=0.001$ ). In our study the stone volumes of the PPSS and PRI groups were calculated as $181.67 \pm 148.41 \mathrm{~mm}^{3}$ and $424.22 \pm 273.22 \mathrm{~mm}^{3}$ $(\mathrm{p}=0.004)$. The reason for the differences in stone volumes calculated in the two studies may be the difference in the volume measurement methods. However, in both studies the statistical differences between the two groups were similar.

Other factors reported in different studies and affecting the spontaneous passage were the secondary signs of ureteral stone that can be detected with NCCT. In a current paper Ahmed et al. reported that spontaneous stone passage was predicted by a lack of hydronephrosis, PFS and TRS. ${ }^{3}$ In the first study related to spontaneous passage and NCCT findings, Takahashi et al. reported that PFS $(\mathrm{p}=0.044)$ and perinephric fluid collection $(\mathrm{p}=0.021)$ were significantly higher in spontaneous stone passage patients. ${ }^{9}$ The perinephric fat stranding observed on NCCT is probably linked to increased lymphatic flow due to increased pressure in the collecting system during acute ureteral obstruction and a rise in intrarenal venous pressure. Pyelovenous and pyelosinus reflux may contribute to perinephric fat stranding. ${ }^{10}$ During the acute phase of obstruction, one of the most important factors responsible for movement of the stone toward the distal is intraluminal pressure. This situation may explain the correlation between spontaneous stone passage and perinephric fat stranding. In our study, similar to that by Takahashi et al., there was a statistically significant difference between perinephric fat stranding and spontaneous passage $(\mathrm{p}=0.049)$.

In $91.17 \%$ of our ureteral stone patients, hydronephrosis was observed. Previous studies have shown a correlation between hydronephrosis and spontaneous passage. ${ }^{3,9}$ The study by Takahashi stated that ureteral stone patients with low grade hydronephrosis were more likely to have spontaneous passage. The reason was that high grade hydronephrosis is a marker of subacute or chronic obstruction and shows a fall in intraluminal pressure reducing peristalsis. In our study, there was a statistically significant correlation between hydronephrosis grade and spontaneous passage $(\mathrm{p}=0.018)$. 
TRS was first described by Smith et al. as ring-shaped soft tissue density surrounding the ureteral stone. ${ }^{11}$ TRS is linked to edema and local inflammation around the ureteral stone. Experimental and clinical research has shown that this edema and inflammation prevents movement of the ureteral stone toward the distal. ${ }^{12}$ A study by Erdogru et al. reported the presence of TRS was important for estimation of spontaneous passage; however there was no statistically significant relationship. ${ }^{6}$ Ahmed et al., as mentioned earlier, showed that the only significant predictors for spontaneous stone passage were the lack of PFS and TRS. ${ }^{3}$ In our study, in 22 patients (+) for TRS only $4(18.2 \%)$ had spontaneous passage, while of the 12 patients (-) for TRS $9(75 \%)$ had spontaneous passage $(\mathrm{p}=0.002)$.

In our study spontaneous passage was not found to be related to patient age, sex, stone direction, density, thickening of renal fascia, DRPA, UD/OUD and widest ureteral diameter. The basic mechanism of one of the parameters, DRPA, is the reduction in the density of renal parenchyma due to development of edema, increased renal lymphatic flow, fluid collection in the renal interstitial area and development of hyperemia after obstruction on the symptomatic side. ${ }^{13}$ However, there was no statistically significant difference identified between DRPA and spontaneous passage. The greater occurrence of this symptom in a chronic period may be the reason for this result.

\section{Conclusions}

In patients with $4-10 \mathrm{~mm}$ diameter ureteral stones, distinguishing patients who will require intervention from those who will spontaneously pass the stone is important. Evaluation of these patients with NCCT provides important clues. In addition to the longest diameter of the stone in the axial plane, the stone volume is an important criterion for spontaneous passage. In addition to stone size and localization, secondary signs identifiable on NCCT may help to predict stones that will pass spontaneously. Small size of the stone, distal location, lack of hydronephrosis, presence of perinephric fat stranding and absence of TRS are findings in favor of spontaneous passage. When the volume cutoff is taken as $295 \mathrm{~mm}^{3}$, the sensitivity to determine spontaneous passage of stone is $84.6 \%$. After this screening process, to determine which stones will pass the presence of perinephric fat stranding and absence of TRS may be used with specificity and positive predictive value of $100 \%$. The presence of perinephric fat stranding and absence of TRS may lead the way to determining which ureteral stones will not require intervention. However, due to our low number of patients and samples, there is a need for broader series studies and multi-institutional study design on this topic.

\section{CONFLICT OF INTEREST}

None of the contributing authors have any conflict of interest, including specific financial interests or relationships and affiliations relevant to the subject matter or materials discussed in the manuscript.

\section{REFERENCES}

[1] Romero V, Akpinar H, Assimos DG. Kidney stones: a global picture of prevalence, incidence, and associated risk factors. Rev Urol 2010;12:e86-e96.

[2] Holman CDJ, Wisniewski ZS, Semmens JB, Bass AJ. Changing treatments for primary urolithiasis: impact on services and renal preservation in 16679 patients in Western. BJU Int 2002;90(1):7-15.

[3] Ahmed AF, Gabr AH, Emara AA, Ali M, Abdel-Aziz AS, Alshahrani S. Factors predicting the spontaneous passage of a ureteric calculus of <10 mm. Arab J Urol 2015;13(2):84-90.

[4] Turk C, Knoll T, Petrik A, Sarica K, Skolarikos A, Straub M, et al. Guidelines on urolithiasis [Internet]. Anheim (NL): European Association of Urology; c2014. [cited 2015 Aug 5]. http://uroweb.org/wp-content/uploads/22-Urolithiasis_LR.pdf.

[5] Sancak EB, Resorlu M, Celik O, Resorlu B, Gulpinar MT, Akbas A, et al. Accuracy of Unenhanced Computerized Tomography Interpretation by Urologists in Patients with Acute Flank Pain. Urol Int 2015;94(2):210-4.

[6] Erdodru T, Aker O, Kaplancan T, Erodlu E. Predictıve role of non-contrast spiral computerized tomography on spontaneous passage of ureteral stones. Int Braz J Urol 2002;28(6):516-21.

[7] Coll DM, Varanelli MJ, Smith RC. Relationship of spontaneous passage of ureteral calculi to stone size and location as revealed by unenhanced helical CT. Am J Roentgenol 2002;178;101103. 
[8] Zorba OU, Ogullar S, Yazar S, Akca G. CT-Based Determination of Ureteral Stone Volume: A Predictor of Spontaneous Passage. J Endourol 2016;30(1):32-6.

[9] Takahashi N, Kawashima A, Ernst RD, Boridy IC, Goldman SM, Benson GS, et al. Ureterolithiasis: can clinical outcome be predicted with unenhanced helical CT? Radiology 1998;208:97-102.

[10] Dalrymple NC, Casfort B, Raiken DP, ElsasS KD, Pagan RA. Pearls and pitfalls in the diagnosis of ureterolithiasis with unenhanced helical CT. RadioGraphics 2000,20:439-447.

[11] Smith RC, Rosenfield AT, Choe KA, Essenmacher KR, Verga M, Glickman MG, et al. Acute flank pain: comparison of non-contrast-enhanced CT and intravenous urography. Radiology 1995;194(3):789-94.

[12] Borghi L, Meschi T, Amato F, Novarini A, Giannini A, Quarantelli C, et al. Nifedipine and methylprednisolone in facilitating ureteral stone passage: a randomized, double-blind, placebocontrolled study. J Urol 1994;152(4):1095-8.

[13] Ozer C, Yencilek E, Apaydin FD, Duce MN, Yildiz A, Erdem E, et al. Diagnostic value of renal parenchymal density difference on unenhanced helical computed tomography scan in acutely obstructing ureteral stone disease. Urology 2004;64(2):223-7. 7. 